\title{
Thermal tumor ablation therapy:Implications in Radio and Chemo-sensitization
}

\section{Deepak kumar}

Department Of Surgical And Biomedical Sciences, India

Corresponding Author : Deepak Kumar, Department Of Surgical And Biomedical Sciences, India. E-mail: deepakkumar@gmail.com

Received date: October 11,2017;Accepted date : October 28,2017; Published date: November 08,2017.

Citation for this Article: Deepak kumar , Thermal tumor ablation therapy: Implications in Radio and Chemo-sensitization , J Cancer Research and

Cellular Therapeutics, Doi: 10.31579/2640-1053/002

Copyright : (c) 2017 Deepak kumar. This is an open-access article distributed under the terms of The Creative Commons Attribution License, which permits unrestricted use, distribution, and reproduction in any medium, provided the original author and source are credited.

\section{Abstract}

It is well established that tumors are unable to grow beyond a certain size $(1-2 \mathrm{~mm})$ unless they acquire their own blood supply via angiogenesis. Also, angiogenesis helps tumors to invade adjacent tissues and metastasize to distant sites [1]. Therefore, it has been postulated that interfering with the blood supply using anti-angiogenic therapies will destroy the tumor [2]. However, there is an emerging alternative concept that depriving the tumor of its blood supply interferes with the delivery of chemotherapeutic agents to the tumor and creates an unfavorable hypoxic environment that compromises the action of radiotherapy [3]. This concept was supported by the modest responses to anti-angiogenic therapies in clinical trials and the lack of any impact on patient's survival when antiangiogenic drugs are administered as single agents [4]. Although, Hurwitz et al. [5] have shown that combining the antiangiogenic drug, bevacizumab with chemotherapy significantly improved survival among metastatic colorectal cancer patients. Still, other studies demonstrated reductions in tumor concentrations of chemotherapy or effectiveness of radiotherapy when antiangiogenic drugs were co-administered [6-8]. Even when antiangiogenic drugs yielded significant effects on the growth of some tumors such as renal cell carcinoma, cervical cancer, and ovarian cancer, they failed to demonstrate significant improvements in patients' survival $[9,10]$. Furthermore, complete resistance to antiangiogenic therapies has been reported for prostate and pancreatic adenocarcinoma and melanoma that might be attributed to the redundant involvement of several angiogenic factors that are difficult to be targeted by a single anti-angiogenic agent in some tumors [11-13]. To explain this inconsistency, further research is needed for better understanding of the underlying cellular and molecular mechanisms of tumor vascularization and its interaction with cancer therapies in different tumor beds.

\section{Introduction}

Tumors' blood vessels are often larger and more conspicuous than those of normal tissues [14]. However, tumors tend actually to have less blood supply than normal tissues because tumor blood vessels are fragile, leaky, morphologically abnormal and malfunctioning $[15,16]$. While the normal vasculature consists of evenly spaced, welldifferentiated arteries, arterioles, capillaries, venules, and veins, the tumor vasculature is heterogeneous, unevenly distributed and chaotic with a tortious irregular course that leads to zones of hypoxia and acidosis [17]. Tumors initiate a vascular supply through secreting angiogenic factors, mainly vascular endothelial growth factor [VEGF] [18]. Despite being of critical value in controlling the physiological processes of angiogenesis and vascular permeability [19], when continuously over-expressed in tumor tissues, VEGF induces accelerated, and defective angiogenesis wherein vessels are immature, leaky, tortious and characterized by disturbed anatomy and physiology [20]. These structural abnormalities contribute to spatial and temporal heterogeneity in tumor blood function, resulting in poorly perfused and subsequently hypoxic tumor microenvironment. To date, no specific molecules have been shown to be expressed exclusively by tumor endothelial cells. However, several molecules are overexpressed in tumor endothelial cells compared with normal endothelium such as VEGF/VEFGFR-2, integrins alpha v5 and alpha 5b1, endoglin, [CD105], thrombospondin-1 receptor [CD36], Thy-1, phosphatidylserine, prostate-specific membrane antigen [PSMA], and multiple tumor endothelial markers [TEMs] [21]. Such disturbances in these growth factors create a chaotic microenvironment that promotes unrestrained angiogenesis and vascular abnormalities.

\section{Targeting fumor vessels}

Targeting tumor vessels via anti-VEGF/VEGFR drugs have not been effective as a cure since impeding tumor blood supply deprives the tumor of oxygen, leading to hypoxia and acidosis, enhanced tumor growth, abnormal angiogenesis, and metastasis and also compromise the cytotoxic functions of immune cells that infiltrate tumors [22]. Reduced tumor vascularity is a primary contributor to therapeutic resistance in cancer since it interferes with the delivery of anti-cancer agents to the tumor targeted by chemotherapy and minimizes the production of reactive oxygen species (ROS) in the tumor area, which is essential for radiation therapy induced cell killing $[23,24]$. Radiation-induced effects on cancer are brought about by inducing ROS production, DNA damage and apoptosis [25]. However, poor vascularization and hypoxia that characterizes solid tumors cause resistance to radiotherapy and are positively correlated with more invasion and metastasis [15]. This effect is achieved by two mechanisms: first, through the lack of $\mathrm{O}_{2}$ and hence the interference with radiation-induced ROS production. Second, via the hypoxia inducible factor- $1 \alpha$ (HIF-1 $\alpha$ ) that provokes adaptive intracellular responses that, in turn, facilitate cell proliferation, interfere with apoptosis; provide protection from cell demise and ultimately rendering tumors radioresistant [26]. The third mechanism that has been recently described in hypoxic tumor tissues is their ability to switch the mode of vascular formation from local sprouting angiogenesis to vasculogenesis which is the formation of blood vessels from circulating cells. This adaptive mechanism allows tumor tissues to evade the anti-angiogenic effect of radiation, rendering the tumor more resistant to radiotherapy [27]. As a result, increasing the chemotherapeutic doses or strategies to intensify radiotherapy has been employed to improve the treatment efficacy. 
However, these procedures can potentially lead to a higher risk of severe side effects including significant endothelial cell apoptosis, reduction of vascular density and changes in vessel morphology which exacerbate the hypoxic condition in tumor tissues leading to a viscous circle of hypoxia and treatment resistance [28]. To raise the therapeutic ratio (the ratio between the desirable cytotoxic effects and normal tissue complications), new strategies to enhance chemo and radiosensitivity of cancer are needed. To this end, we need to develop methods to improve tumor blood perfusion and normalize vascular development to increase tumor vulnerability to anti-cancer therapy as a better alternative to starving a tumor of its blood supply, which is not curative. Furthermore, one needs to emphasize that antiangiogenic drugs are not without side effects. Indeed, they have been reported to induce a myriad of toxic effects such as hypertension, hemorrhage, thromboembolism, proteinuria, malaise, fatigue, biochemical hypothyroidism, and cardiac failure; all are related to the non-specific action of antiangiogenic drugs that affects both normal and cancer tissues [4].

Tumor vasculature is functionally different than normal tissues' blood vessels. It is not merely the copious blood perfusion that induces tumor growth. Rather, enhanced tumor growth occurs in response to nurturing molecules produced by tumor-associated endothelial cells such as the unbalanced production of VEGF(s). However, due to the non-specificity of the current anti-VEFGF/VEGFR drugs and the treatment-resistant hypoxic environment after depriving the tumor of its blood supply, discovering new therapeutic targets in the tumorassociated endothelial cells is warranted [29]. Recently, Notch receptor and its ligand Jagged-1 have been identified as key regulators of tumor angiogenesis. Studies on blocking notch and Jagged-1 signaling demonstrated tumor growth inhibition. However, this was accompanied by an increase in the number of non-functional vessels and poor tumor perfusion [30]. Thus, it is conceivable that ideal targets would be molecules or growth factors that are produced only by tumor-associated endothelial cells that can be blocked to normalize tumor vasculature without obstructing tumor blood supply, altering oxygen delivery or sheltering the tumor from chemotherapy.

\section{Results}

In addition to overexpressing tumor growth promoting factors, tumorassociated endothelial cells lack specific protein complexes that connect endothelial cells together such as the vascular endothelial adhesion molecule, VE-cadherin [31]. Alteration in these complexes causes leakage of fluid and molecules out of the vessels resulting in edema and high interstitial pressure and hamper the delivery of cancer therapy and tumor-targeting lymphocytes to the tumor tissue which, in turn, contributes to cancer therapeutic resistance [32]. Therefore, restoring VE-cadherin or other endothelial cell adhesion molecules in tumor-associated blood vessels could be a promising target for vascular normalization in cancer therapies. Besides direct targeting of angiogenic factors, a recent alternative approach involves modification of epigenetic processes. Emerging evidence supports a role of histone deacetylation and DNA methylation in the regulation of angiogenesis. Accordingly, several histone deacetylase (HDAC) and DNA methyltransferase (DNMT) inhibitors are being examined for their anti-angiogenic properties [33]. Also, a new group of microRNAs (miRs) involved in cancer-related aberrant angiogenesis, hypoxia, and cancer metastasis has been recently discovered. These miRs are referred to as angio miRs and hypoxa miRs, and they stand as promising new therapeutic targets in cancer [34].

A new venue that we believe is worth exploration is physical exercise as a non-pharmacological novel adjuvant therapy to normalize tumor blood vessels, restore their normal structure and function and subsequently increase tumor sensitivity to cancer treatment. The foundation of this assumption comes from the strong epidemiological and experimental evidence supporting the role of exercise in improving blood flow and tissue perfusion in normal and postischemic tissues [35-38]. Exercise elevates the intravascular shear stress which in turn activates endothelial cell production of vasodilators [39].
Some vasodilators have been shown to increase in response to exercise. However, two compounds stand out as central mediators of exercise action: nitric oxide (NO) and prostacyclin [40]. Exercise-induced vasodilation increases tissue hyperemia and oxygenation which subsequently normalizes the microenvironment and induces the formation of new well-developed, normal-functioning blood vessels. This proangiogenic effect of exercise has been proposed to be mediated through several angiogenic factors such as VEGF, angiopoietin 1 and 2 , PPARgamma coactivator-1alpha, cAMP- and cGMP-independent smooth muscle relaxation [40-42]. Exercise has been shown to restore the balance between pro and antiangiogenic factors which promotes a shift towards normalized tumor microenvironment.

Intriguingly, emerging data indicate that aerobic exercise improves tumor perfusion and cancer therapy efficacy and reduces tumor metastasis in preclinical prostate and breast cancer models [43-45]. In a prospective cohort of 571 men with prostate cancer, Van Blarigan et al. demonstrated that physical activity normalized tumor vessel density, size and shape [46]. Hypoxia and its associated biomarkers have been recognized as independent predictors for aggressive behavior and therapeutic resistance in breast and prostate cancer as well as bladder, cervical and nasopharyngeal carcinomas. Thus, these types of cancer are expected to benefit the most from perfusion improving interventions [47]. Despite this progress in unraveling the effect of exercise in improving cancer perfusion and treatment sensitivity, we do not see exercise being recommended for cancer patients who are more likely to have complications that discourage them from exercising. Probably if more clinical trials succeeded to prove that exercise synergizes with cancer therapy, there would be a great boost for patients to exercise and for oncologists to recommend exercise for their patients.

\section{Conclusion}

It is imperative to understand the underpinnings of tumor vascularity and microenvironment. Tumor blood vessels, albeit malfunctioning, they are the portal to deliver drugs to cancer tissues thus, instead of targeting tumor vessels for elimination, functional enhancement might be tried instead. Identifying novel therapeutic targets and interventions to normalize tumor vascular bed should make it possible to enhance the efficacy of cancer chemo and radiotherapies.

\section{References}

1. Leite de Oliveira R, Hamm A, Mazzone M. Growing tumor vessels: more than one way to skin a cat - implications for angiogenesis targeted cancer therapies. Mol Aspects Med. 2011;32(2):71-87. doi: 10.1016/j.mam.2011.04.001.

2. Siemann DW, Horsman MR. Vascular targeted therapies in oncology. Cell and tissue research. 2009;335(1):241-8. doi: 10.1007/s00441-008-0646-0.

3. De Bock K, Cauwenberghs S, Carmeliet P. Vessel abnormalization: another hallmark of cancer Molecular mechanisms and therapeutic implications. Curr Opin Genet Dev. 2011 Feb;21(1):73-9. doi: 10.1016/j.gde.2010.10.008.

4. Jayson GC, Kerbel R, Ellis LM, Harris AL. Antiangiogenic therapy in oncology: current status and future directions. Lancet. 2016. doi: x.doi.org/10.1016/S0140-6736(15)01088-0.

5. Hurwitz H, Fehrenbacher L, Novotny W, Cartwright T, Hainsworth J, Heim $\mathrm{W}$, et al. Bevacizumab plus irinotecan, fluorouracil, and leucovorin for metastatic colorectal cancer. The New England journal of medicine. 2004;350(23):2335-42.

6. Ma J, Pulfer S, Li S, Chu J, Reed K, Gallo JM. Pharmacodynamicmediated reduction of temozolomide tumor concentrations by the angiogenesis inhibitor TNP-470. Cancer research. 2001;61(14):54918.

7. Murata R, Nishimura Y, Hiraoka M. An antiangiogenic agent (TNP470) inhibited reoxygenation during fractionated radiotherapy of murine mammary carcinoma. Int $\mathbf{J}$ Radiat Oncol Biol Phys. 1997;37(5):1107-13. 
8. Fenton BM, Paoni SF, Ding I. Effect of VEGF receptor-2 antibody on vascular function and oxygenation in spontaneous and transplanted tumors. Radiotherapy and oncology: journal of the European Society for Therapeutic Radiology and Oncology. 2004;72(2):221-30.

9. Hutson TE, Escudier B, Esteban E, Bjarnason GA, Lim HY, Pittman KB, et al. Randomized phase III trial of temsirolimus versus sorafenib as second-line therapy after sunitinib in patients with metastatic renal cell carcinoma. Journal of clinical oncology: Official Journal of the American Society of Clinical Oncology. 2014;32(8):760-7.

10. Ledermann JA, Embleton AC, Raja F, Perren TJ, Jayson GC, Rustin GJ, et al. Cediranib in patients with relapsed platinumsensitive ovarian cancer (ICON6): a randomised, double-blind, placebo-controlled phase 3 trial. Lancet. 2016;387(10023):106674.

11. Kindler HL, Niedzwiecki D, Hollis D, Sutherland S, Schrag D, Hurwitz H, et al. Gemcitabine plus bevacizumab compared with gemcitabine plus placebo in patients with advanced pancreatic cancer: phase III trial of the Cancer and Leukemia Group B (CALGB 80303). J Clin Oncol. 2010 Aug 1;28(22):3617-22. doi: 10.1200/JCO.2010.28.1386.

12. Michaelson MD, Oudard S, Ou YC, Sengelov L, Saad F, Houede $\mathrm{N}$, et al. Randomized, placebo-controlled, phase III trial of sunitinib plus prednisone versus prednisone alone in progressive, metastatic, castration-resistant prostate cancer. Journal of clinical oncology: Official Journal of the American Society of Clinical Oncology. 2014;32(2):76-82.

13. Moens S, Goveia J, Stapor PC, Cantelmo AR, Carmeliet P. The multifaceted activity of VEGF in angiogenesis - Implications for therapy responses. Cytokine Growth Factor Rev. 2014;25(4):47382. doi: 10.1016/j.cytogfr.2014.07.009.

14. Dudley AC. Tumor endothelial cells. Cold Spring Harbor perspectives in medicine. 2012;2(3): doi: 10.1101/cshperspect.a006536.

15. Carmeliet P, Jain RK. Angiogenesis in cancer and other diseases. Nature. 2000;407(6801):249-57.

16. Baluk P, Hashizume H, McDonald DM. Cellular abnormalities of blood vessels as targets in cancer. Current opinion in genetics \& development. 2005;15(1):102-11.

17. Hashizume H, Baluk P, Morikawa S, McLean JW, Thurston G, Roberge $\mathrm{S}$, et al. Openings between defective endothelial cells explain tumor vessel leakiness. The American journal of pathology. 2000;156(4):1363-80.

18. Relf M, LeJeune S, Scott PA, Fox S, Smith K, Leek R, et al. Expression of the angiogenic factors vascular endothelial cell growth factor, acidic and basic fibroblast growth factor, tumor growth factor beta-1, platelet-derived endothelial cell growth factor, placenta growth factor, and pleiotrophin in human primary breast cancer and its relation to angiogenesis. Cancer research. 1997;57(5):963-9.

19. Nagy JA, Dvorak AM, Dvorak HF. VEGF-A and the induction of pathological angiogenesis. Annual review of pathology. 2007;2:251-75.

20. Nagy JA, Benjamin L, Zeng H, Dvorak AM, Dvorak HF. Vascular permeability, vascular hyperpermeability and angiogenesis. Angiogenesis. 2008;11(2):109-19. doi: 10.1007/s10456-008-9099-z.

21. McDonald DM, Choyke PL. Imaging of angiogenesis: from microscope to clinic. Nat Med. 2003;9(6):713-25.

22. Jain RK, Duda DG, Clark JW, Loeffler JS. Lessons from phase III clinical trials on anti-VEGF therapy for cancer. Nature clinical practice Oncology. 2006;3(1):24-40.

23. Bottaro DP, Liotta LA. Cancer: Out of air is not out of action. Nature. 2003;423(6940):593-5.

24. Bristow RG, Hill RP. Hypoxia and metabolism. Hypoxia, DNA repair and genetic instability. Nat Rev Cancer. 2008;8(3):180-92. doi: $10.1038 / \mathrm{nrc} 2344$
Bromfield GP, Meng A, Warde P, Bristow RG. Cell death in irradiated prostate epithelial cells: role of apoptotic and clonogenic cell kill. Prostate cancer and prostatic diseases. 2003;6(1):73-85.

26. Semenza GL. Targeting HIF-1 for cancer therapy. Nature reviews Cancer. 2003;3(10):721-32.

27. Brown JM. Vasculogenesis: a crucial player in the resistance of solid tumours to radiotherapy. Br J Radiol. 2014;87(1035):20130686. doi: 10.1259/bjr.20130686.

28. Cameron AC, Touyz RM, Lang NN. Vascular Complications of Cancer Chemotherapy. Can J Cardiol. 2016 Jul;32(7):852-62. doi: 10.1016/j.cjca.2015.12.023.

29. Carmeliet P, Jain RK. Molecular mechanisms and clinical applications of angiogenesis. Nature. 2011 May 19;473(7347):298307. doi: $10.1038 /$ nature 10144 .

30. Sainson RC, Harris AL. Regulation of angiogenesis by homotypic and heterotypic notch signalling in endothelial cells and pericytes: from basic research to potential therapies. Angiogenesis. 2008;11(1):41-51. doi: 10.1007/s10456-008-9098-0.

31. Le Guelte A, Dwyer J, Gavard J. Jumping the barrier: VE-cadherin, VEGF and other angiogenic modifiers in cancer. Biol Cell. 2011;103(12):593-605. doi: 10.1042/BC20110069.

32. Padera TP, Stoll BR, Tooredman JB, Capen D, di Tomaso E, Jain RK. Pathology: cancer cells compress intratumour vessels. Nature. 2004;427(6976):695.

33. Shiva Shankar TV, Willems L. Epigenetic modulators mitigate angiogenesis through a complex transcriptomic network. Vascul Pharmacol. 2014;60(2):57-66. doi: 10.1016/j.vph.2014.01.003.

34. Matejuk A, Collet G, Nadim M, Grillon C, Kieda C. MicroRNAs and tumor vasculature normalization: impact on anti-tumor immune response. Arch Immunol Ther Exp (Warsz). 2013;61(4):285-99. doi: 10.1007/s00005-013-0231-4.

35. Joyner MJ, Casey DP. Regulation of increased blood flow (hyperemia) to muscles during exercise: a hierarchy of competing physiological needs. Physiol Rev. 2015;95(2):549-601. doi: 10.1152/physrev.00035.2013.

36. Ashor AW, Lara J, Siervo M, Celis-Morales C, Oggioni C, Jakovljevic DG, et al. Exercise modalities and endothelial function: a systematic review and dose-response meta-analysis of randomized controlled trials. Sports Med. 2015;45(2):279-96. doi: 10.1007/s40279-014-0272-9.

37. Scott BR, Slattery KM, Sculley DV, Dascombe BJ. Hypoxia and resistance exercise: a comparison of localized and systemic methods. Sports Med. 2014 Aug;44(8):1037-54. doi: 10.1007/s40279-0140177-7.

38. Koga S, Rossiter HB, Heinonen I, Musch TI, Poole DC. Dynamic heterogeneity of exercising muscle blood flow and $\mathrm{O} 2$ utilization. Med Sci Sports Exerc. 2014;46(5):860-76. doi: 10.1249/MSS.0000000000000178.

39. Rodriguez I, Gonzalez M. Physiological mechanisms of vascular response induced by shear stress and effect of exercise in systemic and placental circulation. Front Pharmacol. 2014;5:209. doi: 10.3389/fphar.2014.00209

40. Hellsten Y, Nyberg M, Jensen LG, Mortensen SP. Vasodilator interactions in skeletal muscle blood flow regulation. J Physiol. 2012;590(24):6297-305. doi: 10.1113/jphysiol.2012.240762.

41. Chinsomboon J, Ruas J, Gupta RK, Thom R, Shoag J, Rowe GC, et al. The transcriptional coactivator PGC-1alpha mediates exerciseinduced angiogenesis in skeletal muscle. Proc Natl Acad Sci U S A. 2009;106(50):21401-6. doi: 10.1073/pnas.0909131106.

42. Hoier B, Hellsten Y. Exercise-induced capillary growth in human skeletal muscle and the dynamics of VEGF. Microcirculation. 2014;21(4):301-14. doi: 10.1111/micc.12117.

43. Jones LW, Antonelli J, Masko EM, Broadwater G, Lascola CD, Fels $\mathrm{D}$, et al. Exercise modulation of the host-tumor interaction in an orthotopic model of murine prostate cancer. J Appl Physiol (1985). 2012;113(2):263-72. doi: 10.1152/japplphysiol.01575.2011 
Van Blarigan EL, Gerstenberger JP, Kenfield SA, Giovannucci EL, Stampfer MJ, Jones LW, et al. Physical Activity and Prostate Tumor Vessel Morphology: Data from the Health Professionals Follow-up Study. Cancer Prev Res (Phila). 2015;8(10):962-7. doi: 10.1158/ 1940-6207.CAPR-15-0132.

47. Siemann DW, Horsman MR. Modulation of the tumor vasculature and oxygenation to improve therapy. Pharmacol Ther. 2015;153:10724. doi: 10.1016/j.pharmthera.2015.06.006. Physiol (1985). 2013;115(12):1846-54. doi: 10.1152/ japplphysiol.00949.2013.

46. 